ANALES DE LA UNIVERSIDAD DE ALICANTE. HISTORIA MEDIEVAL, N. ${ }^{\circ}$ 16, (2009-2010) (pp. 11-12) I.S.S.N.: 0212-2480

\title{
PRESENTACIÓN Y DESPEDIDA
}

\section{José Hinojosa Montalvo}

En 1982, dos años después de la puesta en marcha de la Universidad alicantina como tal, comenzaba la andadura de la revista Anales de la Universidad de Alicante. Historia Medieval, con el interés de ser un foro de encuentro, publicación y debate de los medievalistas valencianos y españoles, pero también europeos y americanos, dado que el saber no tiene fronteras. Transcurridas casi tres décadas, esta revista ha cumplido con creces este objetivo trazando un camino prometedor, a pesar de las dificultades y los sempiternos problemas de financiación, que en el momento presente no hacen sino complicarse. El área de Historia Medieval del Departamento de Historia Medieval, Historia Moderna y Ciencias y Técnicas Historiográficas de la Universidad de Alicante, plasmaba, a través de los trabajos de sus diferentes miembros, sus principales líneas de investigación, reunía publicaciones originales y punteras del medievalismo ibérico y mostraba su capacidad de englobar artículos originales en un proyecto integro y apasionante de investigar, conocer, difundir y recuperar nuestro pasado medieval. Por eso es ahora, con ocasión de mi jubilación académica, el momento de agradecer a todos y cada uno de los profesionales, compañeros, amigos y alumnos su participación en un proyecto que nació y continúa lleno de ilusión y fe en la historia y su progreso. Por sus páginas discurre el saber de los medievalistas valencianos, aragoneses, catalanes, mallorquines, sicilianos, sardos y napolitanos, que conferían una particular identidad a esta publicación, dando a conocer el patrimonio histórico de la Corona de Aragón. Y, por supuesto, medievalistas de la antigua Corona de Castilla, Portugal, Italia, Francia, Alemania, Estados Unidos, Israel o Argentina, que con sus investigaciones han colaborado a la continuidad de nuestra revista, que es la de todos.

Aquí tengo que recordar con particular cariño al profesor Juan Manuel del Estal, puntal del medievalismo en Alicante desde sus primeros tiempos como Centro de Estudios Universitarios y que desde los inicios se implicó en la edición de la revista. Y quiero evocar muy especialmente a quienes ya no se encuentran entre nosotros y participaron en el comité científico alentando continuamente su publicación, en particular a nuestra querida y llorada amiga María Luisa Cabanes Catalá. 
La revista nació con carácter misceláneo, plural, y desde el primer numero hasta este volumen que tienen en sus manos han sido múltiples los trabajos publicados, centrados básicamente en la Historia Medieval pero también con destacadas incursiones en el terreno de la paleografía, diplomática, latín y arqueología medieval. Quiero resaltar algunos números monográficos como el editado en 1996, en su no 11, dedicado a Jaime II con motivo de celebrarse la incorporación del mediodía alicantino a la Corona de Aragón; o el n 12 dedicado la Administración y poder en la Corona de Aragón durante la Baja Edad Media, coordinado por J.V. Cabezuelo, mientras que el no 13 lo centramos en el Municipio y centralización monárquica a finales de la Edad Media, preparado por J.A. Barrio. A ellos se añadieron, en fecha más reciente, los números 15, con el título El legado histórico de los judíos de la Corona de Aragón, bajo mi dirección y Leonardo Soler, y el que ahora presentamos Espacios de identidad política urbana en la Península Ibérica, siglos XIII-XV, coordinado, de nuevo, por J.A. Barrio. El objetivo de estos números monográficos era focalizar la atención en temas de interés y debate historiográfico de actualidad en el medievalismo ibérico. La dirección de la revista tratará de mantener esta línea en el futuro.

La revista se encuentra indexada en las principales bases de datos, International Medieval Biblography, Regesta Imperii, Repertorio del Medievalismo Hispánico, Regesta Imperii, Dialnet, amén de portales científicos del Ministerio de Ciencia e Innovación, y tiene todos sus números digitalizados en el Repositorio Institucional de la Universidad de Alicante.

Me gustaría resaltar que desde el inicio de la revista se dejó un espacio abierto a los jóvenes investigadores que realizaban sus primeras investigaciones en el Área de Historia Medieval bajo mi dirección y al hilo de la renovación historiográfica que se producía en la Comunidad Valenciana en la década de los años ochenta. Unos y otros, los que han continuado en el ámbito universitario, los que se han formado en instituciones de educación secundaria, archivos y museos, entre otros, junto con sus alumnos presentes y futuros tendrán que participar en la edición y modernización de la revista.

Estoy seguro que la revista tiene que continuar su periplo, quizás con los cambios formales, institucionales y académicos que piden los nuevos tiempos y la reglamentación auspiciada por las instituciones científicas, pero con una de sus señas de identidad: la difusión de investigaciones originales y la persecución de realizar compendios monográficos que radiografíen procesos históricos, enfoques y líneas metodológicas y analíticas modernas y debates historiográficos. Razones académicas me obligan a dejar la dirección de la revista, que queda en las mejores manos y a la que auguro los mejores éxitos. A todos, colaboradores y lectores de estos pasados años y del presente, gracias. Y no dejen de seguir leyéndonos y consultándonos. 